\title{
Healthy Heart
}

\author{
JB Gupta* \\ Ramjas College, University of Delhi, India
}

Submission: December 09, 2017; Published: January 17, 2018

*Corresponding author: JB Gupta, Ramjas College, University of Delhi, India, Email: jbgupta2011@gmail.com

\begin{abstract}
There is an old saying that health is wealth. Every organ of a human being is important. But heart is the most sensitive organ. Increased blood pressure and blockage of arteries are the two important symptoms of the heart problem. The present article is intended for the benefit of the common man to guide him to maintain a healthy heart, reducing his chances to fall ill and to seek medical remedies.
\end{abstract}

Keywords: Guidance for healthy heart

\section{Opinion}

This article is concerned mainly with the problems of the healthy functioning of the most important and the sensitive organ, the heart of a human being. At the outset, I wish to assert that I am not a cardiologist, nor a doctor with a medical degree. However, I am a qualified scientist of long standing with knowledge and experience of several fields of the modern man. It is believed that a Physicist is well qualified to study and analyze the problems of other fields as well, since Physics imparts a broad understanding of the nature. Observation and analysis of physical phenomena are the basic qualities of a good scientist. Hence the Reader should still find it of some value, which should guide him to live a healthy life, and should save him from the need to visit to a medical doctor for a serious heart problem. If one suffers from some heart problem, common in these days, then he is advised to visit a medical doctor and under go treatment in his care. My ideas here may look some what odd, different from the standard descriptions of such problems, but are relevant and useful.

My first observation is regarding the animals. Note that several functions of the various body parts in animals are similar to those in human beings. In science colleges, often the frogs are dissected and their digestive system is studied by the students. Similarly, rats are used for studying the effect of medical formulations and testing their effects on them. The heart valve of a bullock is used by cardiologist for replacement in humans in special cases. It is a common knowledge that the animals, which are endowed with the heart organ, just like in human beings, do not suffer from heart problems. They do not suffer heart attacks and do not die of heart failure. This is a phenomenon worth attention and explanation. I think that this has to do with animal life. The animals live as per the properties imparted to them by Nature. They do not deviate from the rules of nature. In common language one says that they do not have free will. Religious texts point out that they do not incur any sin, and God does not punish them for such sins. The human beings are a special specie having free will, which of course is the gift of nature. But often the humans deviate from the rules of nature. In the long run, this leads them to problems. The conclusion is that live as per rules of nature to live healthy, as far as you can.

My second observation is that one should not look at the problems of heart in isolation. The whole body of a man is one entity. If one organ suffers, it affects the other organs as well, including the functioning of the heart. Take care of your health in all your activity. Food and work and habits and belief, every thing affects health. Also be aware that it is a cumulative effect. It is just like book keeping. Consequence of every action and thought of a man is stored in the body. At one event, the consequence may not be visible, but if repeated, in the long run, it becomes evident and its consequences are inevitable.

My third observation is that the functioning of the lungs is most intimately connected to the functioning of the heart. If you have healthy lungs, the chances are that your heart will be in good shape. For maintaining the expansive power of the lungs, you have to undertake good physical exercise. Morning walks in clean fresh air environment helps it a lot. Yogic (or physical) exercises impart flexibility to the muscles and organs, of the body which go a long way to keep your body in active mode.

I had an occasion to attend to my relation for a few months in a top class hospital, specialty of heart ailments. Therein, besides 
attending to my patient, I used to visit many other patients of heart problems, admitted in the hospital for studying the cause of their heart problems. The most common cause of these patients suffering from artery blockage or heart valve functioning and some other heart related ailments, was that they had some serious problem of family life at home or at office. A sweet family life, free from anxiety and conflict is sine qua non of a healthy heart.

If one is born to healthy parents, free from serious disease, one inherits a healthy heart and clean arteries of blood. But as life progresses, there is wear and tear. Medical science believes that slow blockage of arteries continues in most human beings. The fat is often considered the source of this blockage. So doctors advise less consumption of fats in the food. The non vegetarians are especially prone to the fat deposit problems in the blood arteries. For those who have to depend on animal meat, the medical science suggests good physical exercise in daily routine. This applies to the vegetarians as well, who take a lot of food with abundance of fats. Leafy green vegetables as part of daily food are advised for a healthy heart. Vegetables provide lots of minerals, essential for the equilibrium of these minerals in the body.

The blood pressure is one good measure of one's heart condition. The Unani hakims and vedic doctors study the hand arteries by holding in their hand. They study the blood pressure as well the rhythm of the blood flow. The allopathic doctors use the mechanical or electronic gadget to measure the blood pressure. The increased blood pressure, is an indication of the stress on heart muscles and the blockage of arteries. The ECG test is meant to study the rhythm of the blood flow. The hypertension is the word used to express the increase in blood pressure. This term itself points to the relation of the heart to the tensions in one's life.

The life style of an individual is often related to the heart ailments by the medical science. In this connection while fast food and one rich in fats is ascribed a possible source of the problem. Smoking in any form and tobacco chewing is considered a main contributor of the heart diseases and of the cancer. Consumption of alcohol on daily basis is known to lead to heart problems. Cleanliness, external and internal helps in all situations of life. It saves you from many possible ailments.

Most of the facts cited above are known to the public at large. But the human beings, as I stated above, uses his free will to enjoy the comforts as per his situations and takes it easy for the deviations from Nature's rules. It is easy to advise but difficult to practice, is the common discourse. If you cannot go the whole hog, practice whatever you can and save the heart. Good luck. 